\title{
Validation and clinical relevance of footprint anatomical masking in clubfoot
}

\author{
Claudia Giacomozzi ${ }^{1 *}$, Julie Stebbins ${ }^{2}$, Louise Way ${ }^{2}$ \\ From 4th Congress of the International Foot and Ankle Biomechanics (i-FAB) Community \\ Busan, Korea. 8-11 April 2014
}

\section{Background}

Anatomy-based regionalization of pressure dynamic footprints has been proved to be feasible when accurate kinematic and baropodometric measurements are integrated [1]. The potential of this method is easily understandable when footprints are incomplete or severely altered; however, its thorough validation on healthy and pathologic feet is still required. This study focusses on anatomy-based masking in paediatric clubfoot using the Oxford Foot Model (OFM, [2]), which identifies 5 plantar regions of high clinical relevance in this population. Validation is based on the comparison with traditional geometrical masking using the same 5 regions, applied to young healthy volunteers and clubfeet.

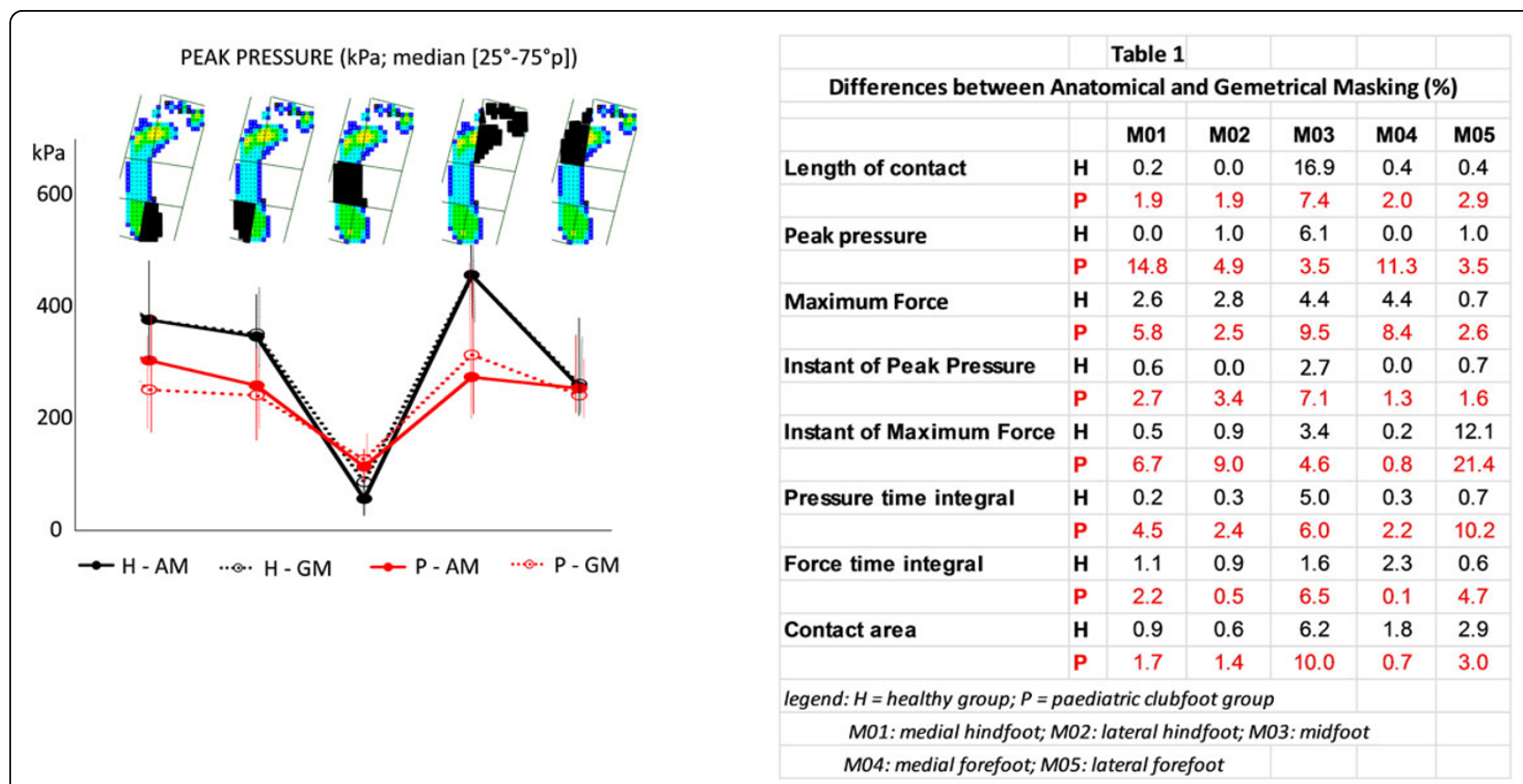

Figure 1 Median values and 25-75 percentile lines of peak pressure at each of the 5 plantar regions (black areas), obtained for the healthy population ( $\mathrm{H}$, black lines) and the paediatric clubfeet $(\mathrm{P}$, red lines) from the anatomical masking (AM, solid lines) and the geometrical masking (GM, dotted lines).

\footnotetext{
* Correspondence: c_giacomozzi@yahoo.com

'Department of Technology and Health, Istituto Superiore di Sanità, Rome, Italy

Full list of author information is available at the end of the article
} 


\section{Materials and methods}

19 healthy volunteers (H: mean age 11.5 years, mean BMI 18.1) and 10 patients with clubfoot (P: mean age 10.8 years, mean BMI 19.9) were examined at the Oxford Gait Lab by using the OFM and an integrated experimental setup based on a VICON motion system and an EMED-m baropodometer. 3-5 footprints per foot were acquired for each individual while walking barefoot at self-selected speed. Markers projection onto the dynamic footprint allowed the anatomical identification (AM) of: medial hindfoot (M01), lateral hindfoot (M02), midfoot (M03), medial forefoot (M04), lateral forefoot (M05). The automatic geometry-based regionalization (GM) which best fitted the OFM definition was used for comparison: it is based on the bisecting line of the foot and on the 23\% (hindfoot) and 55\% (midfoot) perpendicular lines. Relevant baropodometric parameters were calculated for each footprint using AM and GM. To avoid smoothing effects due to intra-subject averaging, all available footprints were used and individually compared; non-parametric statistics was applied to all comparisons.

\section{Results}

143 healthy footprints and 84 clubfoot footprints (17 feet) were used in the study. Results from AM and GM were very similar for the healthy group, for all parameters and regions (median difference 0.9\% [0.4-2.7]) except for midfoot length of contact and lateral forefoot instant of Maximum force; this proved that AM provides comparable results to GM in this population. Interestingly, the corresponding comparison applied to the pathologic group showed higher differences (3.4\% [2.0-6.8]), despite the fact that most feet demonstrated near complete footprints.

\section{Conclusions}

The proposed anatomical masking proved to be comparable to the corresponding geometrical masking on a large selection of healthy footprints. Differences between the two methods for clubfoot footprints suggested the appropriateness and the greater clinical relevance of the anatomical masking, which may better highlight changes in the loading pattern.

\section{Authors' details}

'Department of Technology and Health, Istituto Superiore di Sanità, Rome, Italy. ${ }^{2}$ Nuffield Oxford Orthopaedic Centre, Oxford, UK.

Published: 8 April 2014

\section{References}

1. Giacomozzi C, et al: Med Biol Eng Comp 2000, 38(2):156-63.

2. Stebbins, et al: Gait Posture 2006, 23:401-411.
doi:10.1186/1757-1146-7-S1-A25

Cite this article as: Giacomozzi et al:: Validation and clinical relevance of footprint anatomical masking in clubfoot. Journal of Foot and Ankle Research 2014 7(Suppl 1):A25.
Submit your next manuscript to BioMed Central and take full advantage of:

- Convenient online submission

- Thorough peer review

- No space constraints or color figure charges

- Immediate publication on acceptance

- Inclusion in PubMed, CAS, Scopus and Google Scholar

- Research which is freely available for redistribution

Submit your manuscript at www.biomedcentral.com/submit 